\title{
Tomorrow's Research Library: Vigor or Rigor Mortis?
}

\author{
Richard D. Hacken
}

The gamut of futuristic visions in library literature-from optimistic to pessimistic, from realistic to fanciful. Contradictory answers to recurring questions are found: Can we finally say goodbye to Gutenberg? Will the library card be replaced by the telephone credit card? Will book ownership give way entirely to information access? Will "books without pages" and "libraries without walls" necessarily lead to librarians without jobs? Is it possible to set timetables? After past crystal ball gazers are compared, contrasted, and critiqued, positive plans for progress are suggested.

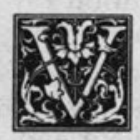

isions of the future are difficult to debunk until the unforeseen arrives. One 1957 journal, for example, featured "The House You'll Live in Tomorrow. ${ }^{\prime \prime}$ Since the tomorrow in question was 1989 , we may now look back with the humor of hindsight to judge the accuracy of the vision. Color illustrations showed a hard glass dome, under which the living quarters swiveled in phase with the sun, maintaining optimum temperature and humidity by solar energy. Children cavorted in the year-round pool, while Sis harvested large heads of lettuce from the hydroponic garden. Mom, dressed in late-fifties chic, sat in her glassed-in "quiet spot" - with TV, intercom and "book-rack" (no electronic publishing in sight!)-and watched the roast self-baste in the radar oven. Dad whirled home from his thirty-hour-aweek job in the family helicopter, skimming past the satellite dish.

In retrospect, we can see that this futurist only made three errors: social, economic, and chronological. In the social realm, he assumed Mom and Sis would continue to be the lone "afficionadas" of the kitchen, while Pop would be the sole breadwinner. Economically, he assumed that anything feasible would be implemented, ignoring the fact that thirty-hour work weeks and gigantic glass domes need to be financed, not just engineered and dreamed. Chronologically, he extrapolated in a straight line from 1957 technology, which correctly presaged a future for microwave ovens and satellite dishes but also predicted hydroponic gardens and family helicopters.

How do the library futurists of today stack up against the futurists of yesterday? More specifically, what can systems analysts, scenario painters, brainstormers, role players, and others tell us-with any accuracy-about research collections of tomorrow? There are valid managerial reasons to look ahead, not the least of which is the will to survive as a profession.

\section{NO BOOKS, NO COLLECTIONS, NO LIBRARIANS?}

Lewis Thomas has commented on how to bring about the collapse of a scientist's career:

I have long believed that there is no scientist alive whose career could not be terminated by an enemy, if the enemy were capable of increasing the laboratory's budget by tenfold or anyfold overnight and, as well, assuring access im-

Richard D. Hacken is European Studies Bibliographer at Brigham Young University, Provo, Utah 84602. 
"Could the library profession, with no truly united plans for orderly growth, be relinquishing its fate to sorcerer's apprentices, even while gleefully scrambling to place money and materials in the path of their burgeoning brooms?"

mediately to any instrument within reach of the victim's imagination. $^{2}$

Might we substitute the word librarian for scientist and automations budget for laboratory's budget to show cause for a similar collection failure? Could the laws of indiscriminate instrumentality come to overrule the instrument users? Could the library profession, with no truly united plans for orderly growth, be relinquishing its fate to sorcerer's apprentices, even while gleefully scrambling to place money and materials in the path of their burgeoning brooms? The answers to these questions may very well depend on whether those in charge of collections have their brooms firmly in hand or whether they are being swept along by them.

Ideas make up the essential core of any research library collection. Since ideas, up to now, have been most readily stored for posterity in symbols found in books, libraries have purchased many books. It now seems possible that ideas can be stored in digital fashion, possibly mixing drawings, photos, text, data, and signals on a single disc. Databases, in addition, not just of bibliographic entries but of entire texts of literature, will come to the terminals of those equipped to receive them. Such are the visions of the future, leaving the survival of any library collections in question. Said A. R. Turnbull of the Edinburgh University Press in a radio broadcast: "While you were watching television, the book died. ${ }^{\prime 3}$

F. W. Lancaster, longtime prophet of the library's coming demise (but not that of the individual librarian-who will apparently flee to the financially more secure electronic suburbs), foresees a "paperless society." An important implication of technological advancement in electronic publishing and distribution, Lancaster believes, will be the "deinstitutionalization" of libraries. Patrons, having learned to search databases and pull in articles and monographs to their terminals with no need for an intermediary-so the argumentation goes-will stay away from book collections. The physical library building will still exist, but as a sort of dinosaur museum, Lancaster predicts, having little to do with the latest research services. Any interim role the library may have in educating the online patron and in facilitating access to information will wither away and crumble shortly after the turn of the millennium. ${ }^{5}$

Nor is Lancaster's a lone voice in the wilderness. One disciple of collection doom, JoAnn Stefani, focuses her attention on the economic facts of life, first pointing to the truism that libraries-in order to garner financial support-are increasingly being asked to prove their immediate and tangible (i.e., marketable) worth in a society largely indifferent to intellectual pursuits. Tax dollars, however, are not the only point of competition; she points to an equally threatening variety of social Darwinism where the collection must adapt or die:

the functions of collection, storage, organization and retrieval of information, which have customarily been performed by librarians, have become the basis for a vast information industry outside the domain of the library, and the librarian must now compete with private interests for information access. ${ }^{6}$

To say that libraries "as we know them" will be imbued with-and possibly even superseded by-succeeding technologies does not seem too far a leap in our "posttypographic culture. ${ }^{17}$ Problems do arise, however, when a time frame starts to emerge that may be too apocalyptically immediate. Consider again the 1957 look at 1989-maybe there will be family helicopters and glass domes, but when? Perhaps the holdings will be mostly in digital storage, but when?

Approximately a decade ago, Lancaster made prognostications about libraries and librarians in the year 2001 that can be mea- 
sured now with exactitude: about half of the time period between that writing and the next millennium has already passed. Yet a like percentage of his vision has not unfolded. He stated, for example, looking back from the fictive viewpoint of 2001, that "by the end of the 1980 s the market for secondary publications in printed form had dwindled to an insignificant level in the developed world. ${ }^{\prime 8}$ Since this sweeping scenario has not materialized, what can we think of his further extrapolation? "By 1995, of course, print on paper had virtually disappeared for all secondary publications, for many of the primary literature of the sciences and the social sciences, and for many types of reference works. ${ }^{\prime \prime}$

Clearly, the underlying technologies are indeed workable and exist here and there in the late eighties. Still, vast and comprehensive electronic databases of literature-like hydroponic gardens-are not yet the rage. Change always seems to take longer than expected. Bibliographic access to traditional collections has grabbed our full attention, while electronic access to primary information itself sits on a back burner. The rate at which technology can be applied to practice is relatively slow; affordability must catch up with availability, actuality with feasibility. Thus the timing errors of Lancaster's forecast may be due to a number of ignored or misread factors, not the least of which are economic: matters of distribution, retooling, profit, copyright innovations, etc.

Despite being continually surprised at the rate at which computer hardware and software make last year's purchases obsolete, I beg to differ with Lancaster when he predicts a "rather fully developed electronic information system" by the year 2000 if not earlier, at least not to the extent that the book becomes a museum piece within the next ten years. ${ }^{10}$

As for the predicted demise of paper, you will find more paper than ever before lurking just a printer cable away from the digital "paperless" wonder. Paper is portable; who knows when electronic readers of the next kind will be as handy and casual as a pile of scribbled or printed notes?
Even when we reach the point that "paper need never exist in this communications environment," 11 chances seem excellent that it will exist. Weyerhaeuser and other lumber companies are still reforesting.

There are precedents for new and old technologies coexisting side by side rather than competing. It has been noted, for example:

Newspapers originally refused to print radio schedules, believing they promoted a competitive medium. Later they found that printing radio schedules led to greater circulation. We need models to account for complementary as well as competitive services. ${ }^{12}$

\section{"It seems logical that the book and the computer will be able to exist si- multaneously, because of-rather than in spite of-their differences."}

In like manner, it seems logical that the book and the computer will be able to exist simultaneously, because of-rather than in spite of-their differences. Thus, for the next several generations at least, "a more plausible prediction than Lancaster's . . . is for a rich interplay between the library as physical repository and new electronic means of distributing information." ${ }^{13}$

Bringing the relationship between the research collection and private suppliers of online information into focus, Richard De Gennaro sees automation in the library not as a source of cutthroat competition or as an imminent threat, but as a symbiosis:

Online searching is not putting libraries out of business; libraries have helped put online searching into business and constitute its principal market. The online services will, in turn, generate new business for themselves and for libraries. ${ }^{14}$

For the present, at least, librarians and the new information entrepreneurs are natural allies-complementary and mutually supportive-who depend on each other's services and products in order to prosper. That picture could change, of course. The information industry of the late $1980 \mathrm{~s}$ is not yet making dinosaurs of our collec- 
tions, but rather "revitalizing them with new technology and services.",15

\section{THE DWINDLING NEED FOR BOOK OWNERSHIP?}

Speaking as if looking back from the year 2000, one prognosticator describes the scene:

Technology had freed information and knowledge services from the library and its associated immobility. It had given them geographical freedom to serve their user. Technology had peeled the covers off the information content of library collections and had given users direct access to this information from locations of their own choosing. Technology had given users analytic, statistical, and logical techniques to work with information; they no longer had to buy it personally because they had access to knowledge networks via screens located for their convenience. ${ }^{16}$

"The core of library servicedispersal of ideas-will have broken loose from the fetters of a physical building to roam the airwaves and optic-fiber byways leading to Everyman. This prospect seems to lead to an increasing emphasis in collection development on access rather than ownership."

By a symbiotic relationship between computers and telecommunications, the core of library service-dispersal of ideas-will have broken loose from the fetters of a physical building to roam the airwaves and optic-fiber byways leading to Everyman. This prospect seems to lead to an increasing emphasis in collection development on access rather than ownership. One observer goes so far as to suggest: "Where we have thought of collections, we must think of connections as the library's means for making material available."17 Without collections, will we be engaged in "connection management" and "cataloging connections?"

Indeed, since "access" seems to be the operative principle of the Brave New Technology, the patron will adapt to on- line services to the extent they are available, affordable, and acceptable: "the user base will have diversified to include a higher proportion of patrons who wish to access the service but spend as little time as possible in the building. ${ }^{\prime 18}$ This would mean (ostensibly) more demands for information not present in the physical book collection with a concomitant remote patron desire for electronic gratification: "Needs will be increasingly met from direct acquisition at time of request, rather than purchase in anticipation of demand." ${ }^{19}$ Librarians will not be as concerned with guessing at what patrons might want to use in the future as with finding a way to supply what they do want to use immediately. Collection budgets will gradually reflect the transfer from predemand stockpiling to ondemand delivery. Such requests may turn the collection from a warehouse into a supermarket, with all the service awareness this entails. The electronic convenience store will presumably be open at all hours.

Collection assessments-so the thoughts go-may well be replaced by database menus, and library cards may be traded in for telephone credit cards. The actual symbolic information signals-as exclusive property of 1984-Plus Industries, a subsidiary of Brave New Technology-would be located digitally within a throbbing mainframe in downtown Los Silicones. The research library would be leasing the permission to access, with an option to download.

Before we consign the concept of research collection ownership to the dustheap of library history, however, let us consider a problem inherent in the concept of remote access. In order for any patron to gain access to ideas, the very core stuff of information, those ideas must be "owned" in their symbolic manifestation, i.e., housed in archival storage, presumably in a permanent fashion. Be they in books, films, electronic impulses, or other types of media, these symbolic representations of information cannot be supplied unless they are preserved. For a library to rely on private business interests to preserve humanity's legacies is to ignore the realities of economic forces and the profit 
motive. As long as it is to the financial advantage for a company to preserve a database or other means of information storage, it will do so. When that same collection (or connection) becomes a liability, it is efficiently excised from the human record, and a tax deduction is all that is left for it to be remembered by. Paradigmatic for this antiarchival tunnel vision was Universal Pictures' destruction of all of its silent films in 1947, "without offering them to any of the local or national film archives." ${ }^{20}$

The fashionable notion of Access über alles thus has a fatal flaw. A library with an established need in a given area of research can never assume that the "other guy, " particularly a for-profit vendor, will continue to fill those patron needs in perpetuity. The only guarantee of access is ownership: "Access always presupposes or depends on ownership-by some party." 21 To the extent research libraries continue to take seriously their archival function-as a necessary precondition to guaranteeing access-they will "collect databases just as seriously as they collect books today-and they will safeguard both." 22

The preservation and integrity of databases are other matters of concern as well. Will the clarion call "Let's burn some books!" be replaced by the suggestion "Let's purge some databases!"? Will the free marketplace of ideas be adversely monopolized by an information system that tends to show only one view? Will there be no room for "alternative" databases and dissenting voices? $?^{23}$ Will the tone of a database shift with prevailing winds or editorial changes of mind? What guarantees will be made that a medium so amenable to change will provide a canon of permanence?

Besides the possibilities of human intervention, the collection manager of the future will want to consider the transient nature of the physical medium on which the ideas are stored symbolically. Storage durations on magnetic tape $e^{24}$ as well as those on optical discs ${ }^{25}$ have been both estimated and proven to be less long-lasting than storage on the most acidic of papers; we are still waiting for the definitive stor- age medium. When that preservation panacea does arrive, who knows whether it will be economically feasible? In the meanwhile we will surely have to rely on our laser-equipped monks for regular recopying as surely as the parchment age relied on its hooded scribes.

\section{HOW CAN WE PLAN FOR THE FUTURE?}

A recurring theme in the literature about future librarianship is the verity that the survival of the profession-though not necessarily of the traditional institutiondoes not depend so much on the rate of automation as on the willingness and ability of librarians to change and adapt. ${ }^{26}$

The prime model for adaptation is the medical profession, which rapidly and smoothly makes use of the latest relevant technologies and pharmaceuticals. ${ }^{27}$ An assumption held in the medical community-and one from which librarians can learn-is that continuing basic research and in-service education are indispensable for the profession. Not every librarian must conduct research into the ways information is being transmitted and into the applications for the profession, but such research must be encouraged and subsidized. On the other hand, professional librarians must be kept apprised of the latest developments in automation and of the impact those developments can exert on the conduct and even redirection of their jobs.

In-service training and retraining will probably be conducted through staff development programs in-house and may emphasize even more of an instructional role toward the patron than at present. ${ }^{28} \mathrm{It}$ is likely that patrons will increasingly require instruction in getting at information not as physically retrievable or selfevident as a book on a shelf. Librarians themselves may need reinstruction on how to instruct. Continuing education will also extend to solving problems and making judgments, since on-the-spot decisions of financial importance will need to be made on a daily basis:

In contrast to the present situation where a library will commit a high proportion of costs well in advance and within an extended time 
frame, decisions on the value and cost of information will increasingly be made at a terminal, with the decision to buy resulting in immediate expenditure. The effects on existing accounting systems will be substantial. ${ }^{29}$

We need a model for those researchers who have relied so much on serendipity, self-help, and interdisciplinary browsing for the humanity of their work. With databases requiring monitored monies per minute for connection time and with no apparent way for them to match the casual browsing ambience of book ranges, will little segments of research innovation and the delights of physically stumbling upon a find be lost to future humans? Will researchers have no equivalent phrase for the following? "I came across a key paragraph while I was leafing through a book someone had left on a table. ${ }^{130}$ Or will automation somehow leave open the possibility of those chance encounters and intuitive connections that-like the chance discovery of penicillin in a bread moldhelp to move humanity forward?

Besides models of new technology, collections may need new models of society or of humaneness to balance the yes/no, on/off, black/white essence of a computerized global information village perched receptively beneath a belt of satellites transmitting in geosynchronous orbit:

Our only chance of an appetizing future . . . lies in the hope that the users of information and chips will be people of wisdom and compassion, balance, humanity and sound moral values. ${ }^{31}$

We need librarians who support the users rather than the system, who see the end as clearly as the means.

We need other models and plans as well, proper questions before we can hope to get adequate answers. If research libraries will have the task of collecting, mounting, and managing large databases, for instance, will these activities be facilitated by current resource-sharing networks, such as OCLC or RLG? What might a comprehensive national plan for implementation look like?

Herbert Landau has suggested that we create a linkage of government and private resources in a "coherent, nonredundant network." A "national infor- mation resource program" would be set up with the following elements:

(1) A national inventory would identify and describe national libraries, databases, and other information archives and resources.

(2) Critical collections would be designated as national information resource centers and given government support as necessary.

(3) The records of the national libraries (Library of Congress, National Library of Medicine, National Agricultural Library) would be linked in an integrated online network and made accessible to the nation at large.

(4) National libraries and newly designated national information resource centers would be oriented to serving the needs of the nation, not of specific governmental bodies.

(5) New national libraries would be designated in areas of critical national need and interest (engineering, education, etc.). Existing libraries with nationally significant collections should be considered for this status, even if they are under private control. The hallmark of the entire effort would be a cooperative enterprise between government (at state and national levels) and the private sector. ${ }^{32}$ By such a system, the expenses and problems of database ownership for access would be distributed among collections (and between connections) just as book ownership is distributed in theory among member institutions by present-day research library utilities.

Ruth Boaz has suggested a similar plan that involves the participation of library schools in the planning phase. ${ }^{33}$

The model of Briscoe and others includes a depository principle broadened to ensure database integrity, physical preservation, and public right to access. This model allows for new applications of the copyright law, whereby "fair use" of databases would include "reuse." Collection managers would need to decide at what level of use it would be more economical to "own" rather than just "access" databases. $^{34}$

Regardless of whether the research and educational models listed above are adopted or not, I suggest that we begin 
now to accept our changing roles. We need to keep abreast of new forms of recorded information, be they on discs or films, in books or boxes. This means new budgetary insights as materials funds are used for software or other means of reading the ideas encoded in various ways. Veneration of the book as a material object will become more and more counterproductive, and patron demand for instructional help with emerging technologies will increase.

At some point, many now discrete functions of the library will likely coalesce. As in-house technical processing recedes into the afterglow of shared-cataloging nirvana, catalogers and other technical processing staff will move toward being managers-rather than producers-of online records. ${ }^{35}$ At the same time, collection development staff will move toward being database access specialists and circulation personnel toward being database usage controllers (regulating delivery, copyright restrictions and so forth). ${ }^{36}$ The databases in question may also include local ones supplied by faculty (upon consultation with collection managers) for local curricular needs or for their own research. ${ }^{37}$ The tasks of reference and collection development will be even more closely aligned than in the past, since the one who learns how to access the database is the logical one to help counsel and guide the researcher. Interlibrary loan and acquisition functions will merge as materials are requested directly through a computer terminal. To the extent collections become less composed of physical holdings and more of electronic storage, the entire library will resemble more and more one conglomerate ILL department.

When these changes will all have occurred nobody can say with any accuracy. This inability to establish timetables has been shown by past crystal ball gazers. But that they will occur seems not to be in question.
As sort of convenience-store proprietors, we who do the jobs of collecting and connecting will always be needed: even if patrons know all about databases and own or lease a number of them, they will look to a research collection for those items too numerous or too expensive to buy. Patrons will look to us increasingly for online access, software, interactive videodiscs, or for whatever else they either cannot afford or are unable to find on the public marketplace.

"Books without pages" and "libraries without walls" do not necessarily lead to librarians without jobs. It need not be said of the research collection, as of the British empire, that it has a great future behind it. Not yet, at any rate. If there is to be competition of Darwinian proportions, we are well equipped to survive. Lester Asheim has pointed out that librarians have acquired, by virtue of their training and experience, advantages over other occupational groups now getting into the information act. Librarians are skilled at techniques of information retrieval. They specialize in all the several aspects of information handling: selection, acquisition, organization, dissemination, and assistance in use. They have motivation as well as skills-they know about searching and delivering, not just about systems. Finally, librarians tend to be peopleoriented. ${ }^{38}$

A defensive attitude toward automation of either the collection records or of the collection itself might be akin to locking and barring the library door to the express trains of new technology. The freight will roll through anyway. A sacrificial attitude means lying down on the tracks to be run over by the streamliner (being railroaded out of the library?). Perhaps the most reasonable approach is to be an active part of the future, taking the offensive and determining directions in which to lay track for the engines of progress.

\section{REFERENCES AND NOTES}

1. Robert G. Beason, "Here's Your House of Tomorrow," Mechanix Illustrated 53, no.6:74-75 June 1957). 
2. Lewis Thomas, Late Night Thoughts on Listening to Mahler's Ninth Symphony (Toronto, New York: Bantam, 1984), p.91.

3. As quoted by James Thompson, The End of Libraries (London: Bingley, 1982), p.76.

4. F. Wilfrid Lancaster, "The Role of the Library in a Paperless Society," Toward Paperless Information Systems (New York: Academic Pr., 1978), p.153-59.

5. F. Wilfrid Lancaster, "Future Librarianship: Preparing for an Unconventional Career," Wilson Library Bulletin 57:748 (May 1983).

6. JoAnn Stefani, "O Weep for Librarianship," Show-Me Libraries 35:32-33 (May/June 1984).

7. Eugene F. Provenzo, Beyond the Gutenberg Galaxy: Microcomputers and the Emergence of PostTypographic Culture (New York: Teachers College Pr., 1986).

8. F. Wilfrid Lancaster and others, "Changing Face of the Library: A Look at Libraries and Librarians in the Year 2001," Collection Management 3:61 (Spring 1979).

9. Ibid.

10. F. Wilfrid Lancaster, "Whither Libraries? or, Wither Libraries," College \& Research Libraries 39:355 (Sept. 1978).

11. Ibid., p.356. Emphasis added.

12. Christine D. Urban, "The Competitive Advantage of New Publishing Formats," in Electronic Publishing Plus: Media for a Technological Future, ed. Martin Greenberger (Washington, D.C.: Annenberg School of Communications, 1985), p.55.

13. Efrem Sigel, "The Future of the Book," in Books, Libraries and Electronics, ed. E. Sigel and others (White Plains, N.Y.: Knowledge Industry, 1982), p.28.

14. Richard De Gennaro, "Libraries, Technology, and the Information Marketplace," Library Journal 107:1051 (June 1, 1982).

15. Ibid. p.1052; 1054 .

16. Ruth M. Davis, "Where will Technology Put the Library of the 21st Century?" Bulletin of the Medical Libraries Association 75:5 (Jan. 1987).

17. Dan Lacy, "Libraries and Access to Information," in Electronic Publishing Plus, p.329.

18. Roy J. Adams, Information Technology and Libraries: A Future for Academic Libraries (London: Croom Helm, 1986), p.96.

19. Ibid., p.97.

20. Dale Pollock, "Collectors: Film Heroes or Villains?" Los Angeles Times, Sept. 16, 1983, as quoted by Peter Briscoe and others, "Ashurbanipal's Enduring Archetype: Thoughts on the Library's Role in the Future," College \& Research Libraries 47:123 (Mar. 1986).

21. Ibid.

22. Ibid. p.124.

23. Paul B. Snider, "Libraries of the Future Kind; or, 1984 Is the Day after Tomorrow," Illinois Libraries 61:715 (Oct. 1979).

24. Gordon R. Williams, "The Function and Methods of Libraries in the Diffusion of Knowledge," Library Quarterly 50:74 (Jan. 1980).

25. William R. Nugent, "Optical Disk Technology," in In Service to Scholarship: Minutes of the One Hundredth Meeting of the ARL (Scottsdale, Ariz., May 6-7, 1982), p.78.

26. See Karen L. Horny, "Managing Change: Technology and the Profession," Library Journal 110:56-58 (Oct. 1, 1985); Allen B. Veaner, "Librarians: The Next Generation," Library Journal 109:625 (Apr. 1, 1984). Note that Veaner's article was published on April Fools' Day 1984.

27. Adams, Information Technology, p.92; Lancaster, "Future Librarianship," p.747-48; and others.

28. Irene B. Hoadley, "The World That Awaits Us: Libraries of Tomorrow," Wilson Library Bulletin 61:24 (Oct. 1986); Adams, Information Technology, p.96.

29. Adams, Information Technology, p.99.

30. Snider, "Libraries of the Future," p.714.

31. Derek Toyne, "People and Books," Library Association Record 88:385 (Aug. 1986).

32. Herbert B. Landau, "The Challenge of the Emerging Information Society: Are We Ready?" in Libraries and Information Science in the Electronic Age, ed. Hendrik Edelman (Philadelphia: ISI Press, 1986), p.36-56.

33. Martha T. Boaz, "Looking Ahead-Managing the Future," in Current Concepts in Library Management (Littleton, Colo.: Libraries Unlimited, 1979), p.282-83.

34. Briscoe and others, "Ashurbanipal's Enduring Archetype," see ref. 20, p.125.

35. Stefani, "O Weep," p.30-31; Adams, Information Technology, p.104.

36. Adams, Information Technology, p.104.

37. Ibid., p.105. 
38. Lester Asheim, "Means and Ends in Librarianship," in Libraries and Information Science, see ref. 32, p.109.

\section{FIFTIETH ANNIVERSARY YEAR 1939-89 \\ IN JANUARY ISSUE OF COLLEGE \& RESEARCH LIBRARIES}

ACRL's Fiftieth Anniversary: For Reflection, for Celebration, and for Anticipation by Edward G. Holley

The Unintended Revolution in Academic Libraries: 1939-1989 and Beyond by Barbara B. Moran

A Statistical History of College \& Research Libraries by Paul Metz

Electronic Information and Technology: Impact and Potential for Academic Libraries by Dilys E. Morris

Information Support for Academic Administrators: A New Role for the Library by Peter G. Watson and Rebecca A. Boone

The Birth of a Network: The Brazilian Struggle

by Janet E. Frederick

Selected Reference Books of 1987-88

by Eileen Mcllvaine 